\title{
A GAMIFICAÇÃO NA EJA: O USO DE METODOLOGIAS ATIVAS EM SALA DE AULA INVERTIDA SÍNCRONA COMO SUBSÍDIO À PRÁTICA DOCENTE
}

\author{
Ulisses Gurgel Costa Júnior ${ }^{1}$
}

RESUMO: Trazer o aluno da EJA numa aula síncrona para abrir sua câmera ou não e participar se tornou um desafio para os profissionais da educação. O objetivo geral é identificar na literatura as contribuições da gamificação, a partir de metodologias ativas em sala de aula invertida síncrona, na Modalidade da Educação de Jovens e Adultos, como subsídio à prática docente. A metodologia desta revisão bibliográfica e documental é pautada no método indutivo e estudo exploratório-descritivo a partir de uma abordagem qualitativa, e se caracteriza buscar por artigos científicos em periódicos, resumos, teses, dissertações já publicadas nas bases de dados. Utilizou-se o cômpito de todos os descritores desta pesquisa com o operador booleano AND nas bases de dados CAPES/MEC, Google Acadêmico e Scientific Electronic Library Online (SciELO). Os trabalhos selecionados foram dispostos em quadro geral para apreciação, análise e discussão. Como instrumento para sintetizar as produções literárias utilizou-se o fichamento. Durante a pesquisa utilizando o operador booleano AND com todos os descritores, é percebido a dificuldade de pesquisa acadêmica, nos repositórios da CAPES/MEC e SciELO, que traga luz à discussão sobre as contribuições da gamificação, a partir de metodologias ativas em sala de aula invertida síncrona, na Modalidade da Educação de Jovens e Adultos, como subsídio à prática docente. Observou-se os resultados pautados nos autores desta revisão, experiências exitosas à prática docente com gamificação em sala de aula síncrona como também a necessidade de haver mais formações sobre como gamificar sua prática, de engajar e motivar o educando.

Palavras-chave: Gamificação. Metodologias Ativas. Prática Docente. Educação de Jovens e Adultos. Sala de Aula Invertida.

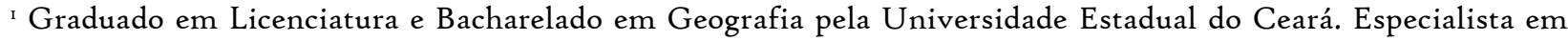
Metodologia do Ensino em História e Geografia pela Faculdade Dom Alberto. E-mail: ulisses.gurgel@educacao.fortaleza.ce.gov.br
} 


\section{INTRODUÇÃO}

A longo dos dez últimos anos vem ocorrendo uma grande transformação de pensamentos, ações e prática na educação pela apreciação de novas metodologias as quais, associadas a Tecnologia de Informação e Comunicação (TICs), passaram a fazer parte de currículos escolares e de Projetos Políticos e Pedagógicos (PPP). Novas nomenclaturas, instrumentais e práticas educacionais inovadoras vieram à tona com a pandemia causada pela SARS-CoV-2 desde março de 2020. Devido a isto, veio o Ensino Remoto Emergencial onde muitas escolas e famílias tiveram que se adaptar a esta realidade desafiadora num curto espaço de tempo e utilizar as ferramentas digitais ao seu alcance a partir de modelos disruptivos de ensino-aprendizagem.

No tocante a este ponto, duas pesquisas apontam o comportamento da população nacional quanto ao uso de aparelhos mobile. A primeira, pelo Instituto Brasileiro de Geografia e Estatística (IBGE), através da Pesquisa Nacional por Amostra de Domicílios (PNAD) de 2019, mostra que 82,7\% dos domicílios possuem acesso a rede e destaca ainda que a principal ferramenta de acesso é o celular (99,5\%) seguido dos computadores (45,1\%), depois pela televisão (31,7\%) e o tablet (12\%) (IBGE, 2019). A segunda, pela Pesquisa Games Brasil (PGB) 2021, 207 mostra o crescimento do mercado de jogos mobile a nível mundial devido o isolamento social causado pela pandemia da SARS-CoV-2 e que no Brasil este setor apresenta em seu público adultos $(40 \%)$ entre 20 a 30 anos, a maioria por mulheres $(52,5 \%)$ onde o smartphone $(4 \mathrm{I}, 6 \%)$ é a plataforma mais utilizada (WAKKA, 2021).

Trazer o aluno da EJA numa aula síncrona para abrir sua câmera ou não e participar se tornou um desafio para os profissionais da educação na Modalidade de Educação de Jovens e Adultos. Diante o exposto, o problema de pesquisa desse estudo se baseia em: quais contribuições encontradas na literatura a gamificação traz à prática docente, na Modalidade da Educação de Jovens e Adultos, em sala de aula invertida nas aulas síncronas? Instigar o professor a se aventurar na gamificação, dentro das metodologias ativas em seu contexto escolar, como contributo à prática docente, pode vir auxiliar, em sala de aula invertida síncrona, a despertar um maior engajamento dos discentes, na Modalidade da Educação de Jovens e Adultos. 
Portanto, o objetivo deste trabalho é identificar na literatura as contribuições da gamificação, a partir de metodologias ativas em sala de aula invertida síncrona, na Modalidade da Educação de Jovens e Adultos, como subsídio à prática docente. Os objetivos específicos discorrem em analisar na literatura as contribuições da gamificação à prática docente e discutir sua utilização em sala de aula invertida síncrona na Modalidade da Educação de Jovens e Adultos.

Levando em consideração que a gamificação está presente na vida do ser humano desde a infância, quando se utiliza de alguns jogos, não apenas como entretenimento, mas objetivando a aprendizagem, o estímulo e o intelecto, e durante toda sua vida despertado pela curiosidade, pela resolução de problemas, pela recompensa ao atingir um objetivo.

Dessa forma, é possível notar que esse estudo sobre gamificação na Educação de Jovens e Adultos e suas contribuições à prática docente pode impactar direta ou indiretamente em novas práticas docentes utilizando a gamificação trazendo benefícios em torno do processo ensino-aprendizagem. Entre estes, um maior engajamento (o aluno fora da caixa); o aumento do interesse pela possibilidade do desafio e de perceber que a partir do erro pode-se chegar à aprendizagem onde o aluno se torna agente na produção de seu próprio conhecimento; a colaboração com os demais colegas e a troca de experiências mútuas entre aluno-professor-paisaluno (porque a gamificação também agrega a família).

O presente artigo de revisão bibliográfica, com base no método indutivo e estudo exploratório-descritivo a partir de uma abordagem qualitativa, se caracteriza buscar por artigos científicos em periódicos, resumos, teses, dissertações já publicadas nas bases de dados. Foram utilizados o cômpito de todos os descritores desta pesquisa com o operador booleano AND nas bases de indexadores CAPES/MEC, Google Acadêmico e Scientific Electronic Library Online (SciELO). Como critério de inclusão nesta revisão estão produções nacionais desde 2020 que relatam, expõe ou discute sobre gamificação, a partir das metodologias ativas, na Modalidade da Educação de Jovens e Adultos como subsídio à prática docente em sala de aula invertida nas aulas síncronas. Os trabalhos selecionados foram dispostos em quadro geral para apreciação, 
análise e discussão. Como instrumento para sintetizar as produções literárias utilizou-se o fichamento.

\section{GAMIFICAÇÃO: ALGUMAS CONSIDERAÇÕES À PRÁTICA DOCENTE NA EJA}

Games é o mesmo que gamificar (Gamification)? A Aprendizagem Baseada em Jogos Digitais utiliza o jogo em si ou todo seu universo para proporcionar a experiência de aprendizagem significativa. De acordo com Kapp (2012, p. 23) “um "jogo" é um sistema no qual os jogadores se envolvem em um desafio abstrato, definido por regras, interatividade e feedback, que resulta em um resultado quantificável, muitas vezes provocando uma reação emocional.”

Não se deve confundir Aprendizagem Baseada em Jogos Digitais com Gamificação, pois, segundo Kapp (2012, p. 23) “Gamification é a utilização de mecânica, estética e pensamento baseados em games para engajar pessoas, motivar a ação, promover a aprendizagem e resolver problemas."

$\mathrm{Na}$ modalidade da Educação de Jovens e Adultos o uso destas ferramentas ativas pelos docentes merece atenção em promover o engajamento e motivação necessários para trazer o aluno vir a participar das aulas. Afirma Alves (2015) que:

É necessário que [...] ofereça ao aprendiz a oportunidade de aplicar, em uma situação real, o conhecimento adquirido para que possa ver o que aprendeu colocado em prática. Ofereça feedback e reforço, a satisfação é baseada em motivação tanto intrínseca quanto extrínseca. (ALVES, 2015, p. 95)

À prática docente, segundo Moran (2006):

É fundamental procurar estabelecer, desde o início, uma relação empática com os alunos, procurando conhecê-los, fazendo um mapeamento dos seus interesses, formação e perspectivas futuras. [...] Vale a pena descobrir as competências dos alunos que temos em cada classe, que contribuições podem dar ao nosso curso. [...] É importante mostrar aos alunos o que vamos ganhar ao longo do semestre, por que vale a pena estarmos juntos. Procurar motivá-los para aprender, para avançar, para a importância da sua participação, para o processo de aula-pesquisa e para as tecnologias que iremos utilizar, entre elas a Internet. (MORAN, 2006, p. 44 e 45)

\section{METODOLOGIA}

Do ponto de vista dos procedimentos técnicos nesta pesquisa de natureza básica, sua base é bibliográfica e documental. Gil (2008), caracteriza este tipo de pesquisa como sendo desenvolvida e construída a partir de materiais já publicados, ou seja, as fontes da revisão bibliográfica são principalmente livros e artigos científicos em periódicos. 
De acordo com Gil (2008, p. 50), “a principal vantagem da pesquisa bibliográfica reside no fato de permitir ao investigador a cobertura de uma gama de fenômenos muito mais ampla do que aquela que poderia pesquisar diretamente”.

Para a produção e orientação das etapas desta pesquisa levou-se em consideração o método indutivo. De acordo com Mazucato (2018)

O método indutivo indica que o caminho que a pesquisa deverá percorrer passará pela seguinte trajetória: a partir da constatação ou levantamento de informações particulares, a pesquisa buscará chegar a um conhecimento mais generalizado. A partir da observação de um conjunto razoável de fenômenos semelhantes, o estudante tentará descobrir uma relação existente entre estes fenômenos e elaborar uma explicação mais generalizante que abarque todos os fenômenos observados (e, também, que possa ser aplicada aos fenômenos semelhantes ainda não observados). (MAZUCATO, 2018, p. 54)

Por se basear na observação dos fatos ou fenômenos, esta pesquisa se trata de um estudo exploratório, na qual Gil (2008, p. 27) diz que "[..] são desenvolvidas com o objetivo de proporcionar visão geral, de tipo aproximativo, acerca de determinado fato" e ao mesmo tempo descritivo, pois, como ressalta Gil (2008, p. 28), este tipo “[..] têm como objetivo primordial a descrição das características de determinada população ou fenômeno ou o estabelecimento de relações entre variáveis".

Apresenta esta pesquisa em sua natureza dos dados uma abordagem qualitativa, que para Minayo (2002):

A pesquisa qualitativa responde a questões muito particulares. Ela se preocupa, nas ciências sociais, com um nível de realidade que não pode ser quantificado, ou seja, ela trabalha com o universo de significados, motivos, aspirações, crenças, valores e atitudes, o que corresponde a um espaço mais profundo das relações, dos processos e dos fenômenos que não pode ser reduzidos à operacionalização de variáveis (MINAYO, 2002, p. 2i e 22).

O levantamento bibliográfico ocorreu entre os dias or e 03 de junho de 2021 nas seguintes bases de dados ou indexadores: Coordenação de Aperfeiçoamento de Pessoal de Nível Superior (CAPES) vinculada ao Ministério da Educação (MEC), Google Acadêmico e Scientific Electronic Library Online (SciELO). Para obter um melhor resultado, a partir das bases de dados, utilizou-se o operador lógico - termo referente a lógica booleana - ou operador booleano AND (intercessão) (Figura I) com os descritores, gerando a partir disto um cômpito dos descritores (Quadro I). 
Figura I - Operador Booleano AND (intercessão)
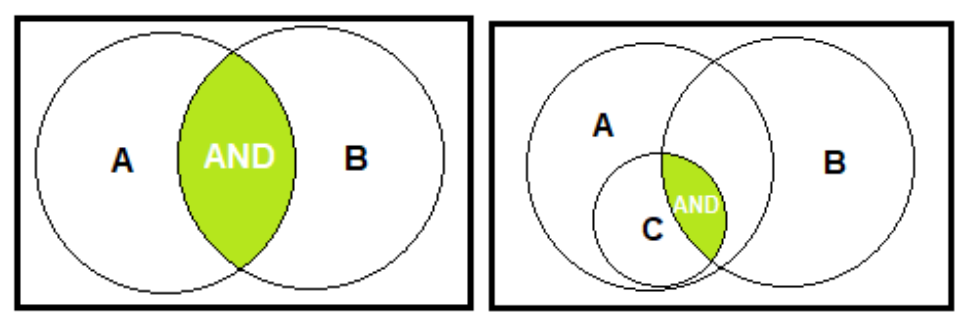

Fonte: Elaborado pelo autor, 202I.

Quadro I - Descritores / Cômpito dos descritores

\begin{tabular}{|c|l|}
\hline DESCRITORES & \multicolumn{1}{|c|}{ CÔMPITO DOS DESCRITORES } \\
\hline Gamificação & $\begin{array}{l}\text { Gamificação AND Educação de Jovens e Adultos AND } \\
\text { Metodologias Ativas AND Prática Docente AND Sala de Aula } \\
\text { Invertida }\end{array}$ \\
\hline $\begin{array}{c}\text { Educação de Jovens e } \\
\text { Adultos }\end{array}$ & $\begin{array}{l}\text { Gamificação AND Metodologias Ativas AND Prática Docente } \\
\text { AND Educação de Jovens e Adultos }\end{array}$ \\
\hline Metodologias Ativas & $\begin{array}{l}\text { Gamificação AND Sala de Aula Invertida AND Educação de } \\
\text { Jovens e Adultos }\end{array}$ \\
\hline Prática Docente & Gamificação AND Metodologias Ativas AND Prática Docente \\
\hline Sala de Aula Invertida & Gamificação AND Educação de Jovens e Adultos \\
\hline
\end{tabular}

Fonte: Elaborado pelo autor, 202I.

Optou-se este operador booleano por refinar os resultados de títulos ou temas que 211 contêm dois, três ou até mesmo todos os descritores desta pesquisa de maneira rápida, confiável e relevante. Segundo Saks (2005):

A principal importância da aplicação dos operadores lógicos booleanos em buscadores na Internet reside na necessidade dos usuários de utilizar esta ferramenta para localizar os documentos que eles desejam recuperar. O sistema de busca booleana ajuda a percorrer documentos, recuperar informações sobre determinados assuntos e localizar recursos informacionais de interesse. Esses recursos apresentam interfaces com centenas de serviços e bancos de dados da Internet, oferecendo formas mais fáceis de localizar informações. (SAKS, 2005, p. 5).

\section{RESULTADOS E DISCUSSÕES}

Quanto a bibliografia, ancorada em artigos científicos em periódicos, resumos em congressos, dissertações e teses, consultadas nas bases indexadoras utilizando o operador booleano AND com todos os descritores (Tabela I), buscou-se como critério de inclusão nesta revisão produções nacionais desde or de janeiro 2020 que relatam, expõe ou discute sobre 
gamificação, a partir das metodologias ativas, na Modalidade da Educação de Jovens e Adultos como subsídio à prática docente em sala de aula invertida nas aulas síncronas.

Tabela I - Resultado da busca através dos indexadores

\begin{tabular}{|c|c|c|c|}
\hline CÔMPITO DOS DESCRITORES & SciELO & $\begin{array}{l}\text { CAPES } \\
\text { MEC }\end{array}$ & $\begin{array}{c}\text { GOOGLE } \\
\text { ACADÊMICO }\end{array}$ \\
\hline $\begin{array}{l}\text { Gamificação AND Educação de Jovens e Adultos } \\
\text { AND Metodologias Ativas AND Prática Docente } \\
\text { AND Sala de Aula Invertida }\end{array}$ & o & 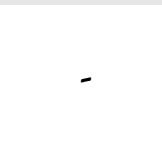 & I64 \\
\hline $\begin{array}{l}\text { Gamificação AND Metodologias Ativas AND } \\
\text { Prática Docente AND Educação de Jovens e Adultos }\end{array}$ & o & - & 467 \\
\hline $\begin{array}{l}\text { Gamificação AND Sala de Aula Invertida AND } \\
\text { Educação de Jovens e Adultos }\end{array}$ & o & - & 202 \\
\hline $\begin{array}{l}\text { Gamificação AND Metodologias Ativas AND } \\
\text { Prática Docente }\end{array}$ & o & - & I.250 \\
\hline Gamificação AND Educação de Jovens e Adultos & o & o & 655 \\
\hline
\end{tabular}

Fonte: Elaborado pelo autor, 2021

Como critério de exclusão estão os trabalhos com data antes de 2020; estudos com trabalhos duplicados; estudos que não sejam referentes a Educação; trabalhos em que não apresentam os descritores utilizados; estudos com título, resumo e justificativa que não atendem com os objetivos geral e específicos e a problemática do presente trabalho.

Algumas observações são necessárias quanto aos indexadores utilizados durante a fase da pesquisa bibliográfica: I- observação - SciELO: apesar de utilizar a lógica booleana AND, este indexador não apresentou, no momento da pesquisa, nenhuma produção literária utilizando o cômpito dos descritores. $2^{\text {a }}$ observação - CAPES/MEC: não utiliza mais do que 2 descritores, o que impossibilitou a consulta; usando o cômpito dos descritores Gamificação AND Educação de Jovens e Adultos não consta trabalhos publicados no momento da pesquisa. $3^{\text {a }}$ observação - Google Acadêmico: utilizando o cômpito com todos os descritores foram encontrados e analisados 164 trabalhos.

Desses, 6 trabalhos que atendendo os critérios de inclusão e exclusão já mencionados, foram selecionados e dispostos em quadro geral para apreciação, análise e discussão. No quadro 
consta o título da produção acadêmica, os autores / ano e os descritores utilizados em cada trabalho acadêmico (Quadro 2)

Como instrumento para sintetizar as produções literárias selecionadas utilizou-se o fichamento. De acordo com Mazucato (2018):

Os fichamentos são material essencial para condução da escrita. Qualquer que seja o seu objetivo, a pesquisa em bibliografias da área de estudo sempre é parte fundamental e os fichamentos, quando feitos de maneira organizada, contribuem para organização do material levantado e lido. (MAZUCATO,2018, p. II)

Quadro 2: Trabalhos analisados que atenderam de alguma forma a problemática e os objetivos geral e específicos do presente artigo

\begin{tabular}{|c|c|c|}
\hline TÍTULO & AUTORES / (ANO) & DESCRITORES \\
\hline $\begin{array}{l}\text { A educação 4.o: Um estudo de } \\
\text { caso acerca da formação de } \\
\text { professores para } \\
\text { enfrentamento dos desafios do } \\
\text { século XXI }\end{array}$ & $\begin{array}{l}\text { LEMES, Isadora Luiz. } \\
\text { SANTOS, Renato P. dos. } \\
(202 \mathrm{I})\end{array}$ & $\begin{array}{l}\text { Formação de Professores. } \\
\text { Educação 4.o. Século } \\
\text { XXI. Oficina. Formação } \\
\text { Continuada. }\end{array}$ \\
\hline $\begin{array}{l}\text { Uma gamificação analógica } \\
\text { para conteúdos teóricos } \\
\text { inspirada em jogos do gênero } \\
\text { card game (CG) }\end{array}$ & CARVALHO et al (202I). & $\begin{array}{c}\text { Educação. Metodologias } \\
\text { Ativas. Tecnologia } \\
\text { Educacional. } \\
\text { Gamificação. }\end{array}$ \\
\hline $\begin{array}{c}\text { O uso das Metodologias } \\
\text { Ativas apoiadas em tecnologia: } \\
\text { uma experiência da prática } \\
\text { docente no IF baiano - campus } \\
\text { Itapetinga }\end{array}$ & $\begin{array}{c}\text { BRITO, Elda Rosa } \\
\text { Rodrigues da Silva. } \\
\text { LOUREIRO, Valéria Jane } \\
\text { Siqueira. } \\
(202 \mathrm{I})\end{array}$ & $\begin{array}{c}\text { Metodologias Ativas. } \\
\text { Tecnologia. } \\
\text { Prática Docente. }\end{array}$ \\
\hline $\begin{array}{c}\text { Utilização de jogos didáticos } \\
\text { para o ensino da tabela } \\
\text { periódica }\end{array}$ & $\begin{array}{l}\text { ALVES, Rafael José. } \\
\text { (2020) }\end{array}$ & $\begin{array}{c}\text { Jogos. Ensino de } \\
\text { Química. Metodologias } \\
\text { Ativas. EJA }\end{array}$ \\
\hline $\begin{array}{c}\text { Metodologias Ativas e as } \\
\text { Tecnologias de Informação e } \\
\text { Comunicação nas práticas } \\
\text { pedagógicas: aprendizagem } \\
\text { baseada em jogos }\end{array}$ & $\begin{array}{l}\text { SIMÕES, Juliana. } \\
(2020)\end{array}$ & $\begin{array}{l}\text { Metodologias Ativas. } \\
\text { Tecnologias da } \\
\text { Informação e } \\
\text { Comunicação. Práticas } \\
\text { Pedagógicas. Jogos. }\end{array}$ \\
\hline $\begin{array}{l}\text { O uso de metodologias ativas } \\
\text { no ensino remoto com alunos } \\
\text { de uma IES durante a } \\
\text { pandemia do covid-I9 }\end{array}$ & PARADA et al (2020). & $\begin{array}{c}\text { Metodologia Ativas. } \\
\text { Ensino Remoto. Covid-ı9. } \\
\text { Ensino de Comunicação. } \\
\text { Tecnologias digitais. }\end{array}$ \\
\hline
\end{tabular}

Fonte: Elaborado pelo autor, 2021 
Lemes e Santos (202I) desenvolveram um Estudo de Caso a partir de uma oficina realizada dentro de uma Universidade, aberta para professores e até mesmo alunos de licenciaturas qualquer, sobre a Formação de Professores no segundo semestre de 2019 buscando a discussão quanto à Educação 4.o, seu conceito e suas perspectivas visando dar suporte inovador à prática docente levado a novas posturas de pensamento e abordagens utilizando de forma ativa as novas metodologias do século XXI.

Diante disso, Lemes e Santos (202I) frisam a importância da compreensão do papel do educador 4.0 em fomentar a criticidade e a importância cidadã dos discentes. Os professores atuariam como facilitadores neste processo estimulando seus alunos a colaborarem entre si e em equipe dando oportunidade de aprenderem em qualquer local, garantindo assim o direito de aprender de acordo com seus interesses e objetivos.

Por fim, Lemes e Santos (202I) lamentam a baixa adesão na oficina reconhecendo que deveria ter havido uma maior divulgação e conclui a importância da participação de um único professor na oficina em que demostrou já fazer uso de 'problemas' e 'desafios' em suas aulas e que pontuou a necessidade de haver mais formações nas quais promovam à prática docente tornar os alunos mais ativos.

Sobre a produção de uma proposta de gamificação roteirizada a partir dos estudos e levantamentos de revisão de literatura, indicada por Carvalho et al (2021), para conteúdos teóricos que podem ser aplicados de maneira flexível para atender várias disciplinas, onde ressaltam que não seria indicado em cálculos matemáticos, a pesquisa se demostrou bastante satisfatória, onde perpassaram por diversos autores base sobre o assunto quanto a importância da utilização de estratégias de gamificação que podem ser utilizadas em salas de aula, síncronas ou assíncronas, inspiradas em jogos do tipo Card Game (CG) como auxílio em motivar o aprendizado dos discentes com seus conteúdos teóricos.

Carvalho et al (202I) ressalta de forma satisfatória da elaboração do roteiro como proposta de uma estratégia gamificada analógica, inspirada em Card Games (CG) na qual atingiram o propósito de chamar a atenção dos discente do ensino fundamental II e médio onde os alunos realmente se sentissem motivados a participar. Foram utilizados alguns elementos do 
universo dos jogos digitais no processo de roteirização tais como o feedback, o desafio, a pontuação, a competição, a progressão, a cooperação entre outros.

O trabalho realizado por Brito e Loureiro (202I) buscou trazer algumas propostas de material didático com base em Metodologias Ativas desenvolvidas no Instituto Federal de Ciências e Tecnologia baiano - campus Itapetinga - tendo como apoio algumas Tecnologias Digitais de Informação e Comunicação (TDIC) e Tecnologias da Informação e Comunicação (TIC) demonstradas em experiências e suas repercussões em métodos utilizados no ensinoaprendizagem dentro da disciplina de Língua Espanhola onde foram destacadas o Ensino por Projetos, Gamificação, Aprendizagem Baseadas em Times (ABT), Aprendizagem Baseada em Problemas (PBL), Ensino Híbrido e Sala de Aula Invertida.

Cada uma dessas Metodologias Ativas foi colocada à experiência em turmas da própria instituição como discorre Brito e Loureiro (202I) por exemplo o projeto para avaliação da aprendizagem, desenvolvido com as turmas do curso Integrado na disciplina de Língua Espanhola e de Especialização em Leitura e Produção Textual aplicadas à Educação de Jovens e Adultos, através da gamificação com a criação de QR Code no qual foi possível não somente verificar o nível de aprendizagem de forma qualitativa e quantitativa, mas também a motivação, o estímulo em resolver os problemas, o trabalho em equipe e articulação entre a teoria e prática a partir das Metodologias Ativas.

Brito e Loureiro (202I) conclui e reafirma que o professor deva realizar certas combinações de métodos, alinhados com a realidade e contexto de seus educandos, repensando sua prática docente, saindo do centro das atenções e trazendo para o foco seu aluno, tornando-o protagonista, o fascínio em participar de forma ativa a partir de inovadoras propostas de aprendizagem.

Nesta linha de pensamento, o trabalho de Alves (2020), a partir do estudo de caso dentro de uma abordagem qualitativa, sobre a aplicação de jogos inseridos nos conteúdos de química numa turma de EJA com 15 educandos do Io ano de uma escola estadual de Itumbiara - GO, verificou-se que para existir uma maior participação do educando na aulas, eles devem ser protagonistas, onde os temas propostos pelos docentes devam coincidir com a realidade e as 
necessidades do educando, utilizando-se ainda de seus conhecimentos prévios e de vida, almejando que a aprendizagem faça sentido no seu dia a dia e que desperte o senso crítico e a curiosidade.

Ainda, Alves (2020), ressalta que o docente da EJA tenha em mente buscar o novo, repensar sua prática e sua ação pedagógica visando trabalhar de forma interdisciplinar a ludicidade, utilizando metodologias ativas, e aprendizagem a partir de atividades de lazer recreativas e envolventes tendo como fundo o diálogo, buscando assim o desabrochar do desejo, $\mathrm{d}$ a vontade e o interesse de seus educandos para o ensino-aprendizagem.

Como conclusão do Estudo de Caso, Alves (2020), destaca que o ensino e aprendizagem dos educandos da EJA pode ser mediada através de diferentes recursos didáticos ao mostrar de forma positiva a utilização de metodologias ativas no ensino com o uso de jogos, no qual o docente, tendo ciência de sua utilização, poderá engajar seus educandos em desenvolver habilidades de inovação, percepção e organização com propósito de atingir o objetivo desejado.

A pesquisa realizada por Simões (2020) buscou trazer o conceito de TICs, o uso de jogos com auxílio de TICs em associação com Metodologias Ativas e seu uso na prática docente e o desenvolvimento de um jogo utilizando QR Code a partir do celular através de uma Metodologia Ativa. Através de uma experiência exitosa, encontrada na revisão bibliográfica, por um professor, atuante numa escola da Prefeitura do Rio de Janeiro e Nova Iguaçu, que desenvolveu atividades de Matemática usando QR Code e obteve feedback muito positivo por parte não apenas dos alunos através da participação, motivação, na resolução dos desafios mas também pela repercussão em toda escola, houve a intenção de desenvolver um jogo, intitulado “Caça ao Tesouro com QR Code”, utilizando as características dos games (meta, regras, feedback e participação voluntária), e mesmo que, por conta da pandemia de Sars-CoV-2 não pode ser realizada, acredita em seu êxito (SIMÕES, 2020).

Conclui sua pesquisa, Simões (2020), ressaltando sobre a importância de trazer as TICs associadas com Metodologias Ativas e os jogos para o âmbito escolar, pois observou-se, através da pesquisa, que a rotina na escola pode ser quebrada e o ensino-aprendizagem flui, quando o educando se torna protagonista e sua realidade é trazida para escola, e quando se busca, através 
de formações e capacitações para os docentes, a dialogar com estes recursos ativos e novas práticas, passa a existir um interesse maior de seus educandos, despertado pela ludicidade, pela resolução de problemas em grupo, pelo desafio, pela competição saudável e pela descontração.

Neste sentido, corroborando com Simões (2020), a pesquisa realizada por Parada et al (2020), descrita a partir de relatos sobre a prática docente dos cursos de Comunicação e Design de uma instituição de ensino superior (IES) no Rio Grande do Sul, durante a pandemia do Covid-ı́ nos meses de março a dezembro de 2020, demonstra a importância do olhar que a instituição teve em trazer à discussão sobre quais metodologias ativas, já aplicadas antes da pandemia, os educandos gostariam para aulas síncronas, dando assim, protagonismo ao educando e proporcionando a parceria entre professor-aluno, com maior feedback, colaboração e motivando sua participação e senso crítico.

Parada et al (2020) menciona que, ao adotar o ensino remoto, os professores tiveram um desafio de instigar e motivar seus alunos a ligarem sua câmera e interagir, participar dos grupos de chat e discussão sobre os conteúdos escolares. Fez-se parceria com a Google For Education para utilizar as ferramentas, tais como Google Meet, Google Classroom, Google Jamboard e outras além destas, como por exemplo o Kahoot, Miro, Canvas, Mentimeter e elementos da gamificação, em suas aulas síncronas no Ambiente Virtual de Aprendizagem (AVA) onde se demonstrou grande afinidade e interatividade pelos educandos. (PARADA et al, 2020).

Apesar de todas as dificuldades enfrentadas por conta da pandemia de Covid-19, o trabalho realizado de forma disruptiva, que contou com as experiências e novas atitudes/práticas dos docentes e as expectativas e envolvimento dos educandos, foi satisfatória pois envolveu professores e alunos, proporcionado pela motivação, engajamento de todos e colaboração em ressignificar o ensino-aprendizagem utilizando recursos das TICs e as Metodologias Ativas no contexto escolar (SIMÕES, 2020).

\section{CONSIDERAÇÕES FINAIS}

O presente artigo objetivou de forma geral identificar na literatura as contribuições da gamificação, a partir de metodologias ativas em sala de aula invertida síncrona, na Modalidade da Educação de Jovens e Adultos, como subsídio à prática docente e objetivou especificamente 
analisar na literatura as contribuições da gamificação à prática docente e discutir sua utilização em sala de aula invertida síncrona na Modalidade da Educação de Jovens e Adultos.

Durante a pesquisa de revisão bibliográfica, por trabalhos acadêmicos relacionados com o cômpito de todos os descritores, que trata este artigo utilizando o operador booleano AND, é percebido a dificuldade de pesquisa acadêmica, nos repositórios da CAPES/MEC e SciELO, que traga luz à discussão sobre as contribuições da gamificação, a partir de metodologias ativas em sala de aula invertida síncrona, na Modalidade da Educação de Jovens e Adultos, como subsídio à prática docente.

Por fim, vale destacar algumas contribuições pautadas nos autores desta revisão, que por ser um assunto muito recente, inovador e desafiador, para os docentes e discentes, na Modalidade da Educação de Jovens e Adultos, é importante pensar em formações continuadas e capacitações sobre Tecnologias Informação e Comunicação e o uso de Metodologias Ativas em sala de aula invertida síncrona, abordando a gamificação e suas contribuições à prática docente, que desperte no docente a possibilidade de promover aulas diferenciadas/personalizadas assim como também à pesquisa acadêmica com esta temática

tendo como pano de fundo o laboratório escolar síncrono em sua vivência, que motive e traga o aluno a esta nova forma de ensino-aprendizagem, possibilitando-o a relações de participação ativa, instigada por desafios e resolução de problemas, colaboração, de socialização e reflexão crítica.

\section{REFERÊNCIAS BIBLIOGRÁFICAS}

ALVES, F. Gamification: como criar experiências de aprendizagem engajadoras: um guia completo do conceito à prática. 2. ed. São Paulo: Dvs Editora, 2015. 238 p.

ALVES, R. J. Utilização de jogos didáticos para o ensino da tabela periódica. 2020. $40 \mathrm{p}$. Trabalho de conclusão de curso (Graduação em Licenciatura em Química) - Instituto Federal de Educação, Ciência e Tecnologia de Goiás, Campus Itumbiara, Itumbiara, 2020. Disponível em: http://repositorio.ifg.edu.br/handle/prefix/589. Acesso em: 03 de jun. 202I. 
BRITO, E. R. R. da S.; LOUREIRO, V. J. S. O uso das metodologias ativas apoiadas em tecnologia: uma experiência da prática docente no IF baiano - campus Itapetinga. In: TEDESCO, M. T.; CORREIA, C. (org.). Contribuições da Semiótica ao ensino de português no mundo. Rio de Janeiro: Dialogarts, 2021. p. I23-I43. Disponível em: http://www.dialogarts.uerj.br/admin/arquivos_tfc_lingua/ContrSemioEnsPortMund.pdf\#pa ge $=123$. Acesso em: 02 jun. 2021.

CARVAlHO, V. H. R; BRITO, J. A.; BITENCOURT, R. B.; AMORIM, D. G. Uma gamificação analógica para conteúdos teóricos inspirada em jogos do gênero card game (CG). Revista de Educação da Universidade Federal do Vale do São Francisco, [S. l.], v. II, n. 24, p. I47-175, 2021. Disponível em: https://www.periodicos.univasf.edu.br/index.php/revasf/article/view/1386. Acesso em: 02 jun. 2021.

GIL, A. C. Métodos e técnicas de pesquisa social. 6. ed. São Paulo: Editora Atlas SA, 2008. 200 p.

IBGE - Instituto brasileiro de Geografia e Estatística. Ministério das Comunicações (MCOM). Brasília, DF: IBGE. Disponível em: https://www.gov.br/mcom/pt$\mathrm{br} /$ noticias/202I/abril/pesquisa-mostra-que-82-7-dos-domicilios-brasileiros-tem-acesso-ainternet. Acesso em: io de jun. 2021.

KAPP, K. M. The gamification of learning and instruction: Game based methods and strategies for training and education. San Francisco: Pfeiffer, 2012. $302 \mathrm{p}$.

LEMES, I. L..; SANTOS, R. P. dos. A educação 4.o: um estudo de caso acerca da formação de professores para enfrentamento dos desafios do século XXI. Revista brasileira de Ensino de Ciências e Matemática, RBECM, Passo Fundo, v. 4, n. I, p. 82-10o, jan./jun. 2021. https://doi.org/I0.5335/rbecm.v4ir.10842

MAZUCATO, T. et al. (Org.). Metodologia da pesquisa e do trabalho científico. Ia. ed. Penápolis: FUNEPE, 2018. 94 p.

MINAYO, M. C. de S. et al. (Org.). Pesquisa Social. Teoria, método e criatividade. 2i ed. Petrópolis: Vozes, 2002. $80 \mathrm{p}$.

MORAN, J. M; MASETTO, M. T.; BEHRENS, M. A. Novas tecnologias e mediação pedagógica. ıo. ed. Campinas, SP: Papirus, 2016. 173 p. 
PARADA, A. R.; PORTAL, V. M. dos S.; RODRIGUES, M. de A. T.; BORBA, E. Z. O uso de metodologias ativas no ensino remoto com alunos de uma IES durante a pandemia do Covid19. Redin - Revista Educacional Interdisciplinar, Taquara: FACCAT, v. 9, n. I, p.137-151, 2020. Disponível em: http://seer.faccat.br/index.php/redin/article/view/r875. Acesso em: or de jun. 202I

SAKS, F. do C. Busca booleana: teoria e prática. 2005. 6I p. Monografia (Especialização em Gestão da Informação), Programa de Pós-graduação em Gestão da Informação - PPGGI, Setor de Ciências Sociais Aplicadas, Universidade Federal do Paraná, Curitiba, 2005.

SIMÕES, J. Metodologias Ativas e as Tecnologias de Informação e Comunicação nas práticas pedagógicas: Aprendizagem baseada em Jogos. 2020. 4I p. Monografia (Especialização em Tecnologia, Comunicação e Técnicas de Ensino) - Universidade Tecnológica Federal do Paraná. Rio Negro, 2020. Disponível em: http://repositorio.utfpr.edu.br/jspui/handle/I/2432I. Acesso em: 03 de jun. 2021.

WAKKA, W. Pesquisa Games Brasil 2021: mostra crescimento do consumo de jogos com isolamento. 2021. Editado por Claudio Yuge. Disponível em: https://canaltech.com.br/games/pesquisa-games-brasil-202I-mostra-crescimento-doconsumo-de-jogos-com-isolamento-I82208/ Acesso em: I9 jun. 2021. 